\title{
La filosofía de J.D. García Bacca
}

\author{
CARLOS BEORLEGUI \\ Universidad de Deusto
}

\section{Un filosofo exilado y no suficientemente conocido}

No resulta fácil dar cuenta en pocas páginas del pensamiento filosófico de Juan David García Bacca, el filósofo más representativo del wexilio republicano", y uno de los más dignos del apelativo de "filósofo" en lengua castellana, como ya afirmó de el José Gaos. ${ }^{1}$ Son varias las razones de tal dificultad. En primer lugar, la amplitud de su obra escrita (supera ampliamente los quinientos títulos) $)^{2}$ y de los temas sobre los que ha reflexionado. Y en segundo término, la variedad de sistemas de pensamiento $\mathrm{y}$ de inflexiones teóricas que ha experimentado su filosofar. En otros trabajos he presentado ya con más amplitud y profundidad, de modo diacrónico y sistemático, los diversos sistemas filosóficos por los que ba evolucionado y la diversidad de influencias que ha ido experimentando. ${ }^{3}$

Por ello, me limitaré en estas páginas a presentar muy brevemente las diferentes etapas de su larga trayectoria filosófica, para centrarme más a fondo en la que considero su etapa más personal e interesante (la que está marcada por la influencia de $K$. Marx), aunque no la definitiva de su cronología vital. Es inevitable, por tanto, dejar fuera muchos aspectos de interés de un pensamiento ciertamente profundo, inquieto, de enorme originalidad, ambición y audacia, por desgracia no suficientemente conocido ni valorado, a pesar de su indudable valía y de las interesantísimas sugerencias filosóficas, de plena actualidad, que su bien construida prosa (a ve- ces, también es verdad, un tanto barroca y abigarrada) brinda al lector.

\section{Las primeras singladuras}

\section{a) Fonnación neotomista}

Garcia Bacca nació en Pamplona (26/VI1901), y acaba de fallecer el 5 de agosto de 1992, en Quito (Ecuador), a los 91 años. Su dilatada vida ha estado marcada por un continuo cambio de residencia, en paralelo y similitud a la enorne versatilidad de su pensamiento. Sus raíces culturales quedan reflejadas por sus propias palabras autobiograficas: «Soy vasco-navarro, nacido en Pamplona, de padres aragoneses, y de formación cultural catalanas. ${ }^{4}$

Muy joven, entra en la orden claretiana de la provincia de Cataluña, donde recibe su primera formación filosófica y teológica, que completará posteriormente en diversas universidades europeas. En Lovaina, completó estudios de filosofía y teología. ${ }^{5}$ Pero también se dedicó a ampliar su formación en diversos ámbitos humanísticos y científicos en $\mathrm{Pa}-$ rís, Friburgo (Suiza), Viena y Munich. En la capital bávara, estudió física nuclear de la mano de $H$. Sommerferld, y biología con el neovitalista $H$. Driesch. Al cabo de este periplo europeo, se hallaba el joven filósofo con una envidiable formación de primera mano en "teologia, filosofía, filología, física, geometría, matemáticas, arte, poesía, literatura, historia, biologia, etc. Conoce el griego, el latín, el alemán, francés, italiano, inglés». ${ }^{6}$

Este amplio abanico de conocimien- 
tos, fruto de su afán por abarcar los más dispares ámbitos del saber, junto con su deseo de unir dialécticamente los saberes científicos con los filosóficoteológicos, van a constituir uno de los rasgos más valiosos, permanentes y personales de toda su trayectoria.

Adcmás, su afán por adentrarse en tan amplios «panoramas intelectuales» estaba alentado por el programa neotomista recibido en la Lovaina del cardenal Mercier, empeñado en instaurar un diálogo en profundidad y sin complejos entre la teologia y todos los demás saberes, en sus más punteros avances e innovaciones. Este ideal teórico fue entusiastamente compartido por el joven navarro, como lo reflejó en la lección inaugural del curso de 1929-1930 en el filosofado de Solsona. ${ }^{7}$ En ese discurso muestra su firme convicción de que la filosofía tomista, debidamente renova$\mathrm{da}$, tiene que seguir siendo la columna vertebral de la filosofía, enriquecida con las aportaciones más valiosas de todas las ciencias humanas y naturales.

Pero tales fervores neotomistas le durarán muy poco, debido a la influencia de la filosofía de Ortega, que lo adespertó de ese sueño dogmático que se llama - que se llamó escolástica, y de este otro sueño dogmático laico, que se llama o llamó axiomática"."

En el segundo sueño dogmático, el de la axiomática, estaba embargado desde que, a su regreso a Cataluña, comenzó a dar clases de Lógica y Filosofía de las Ciencias en la Universidad de Barcelona, de la mano de Serra Húnter y, sobre todo, de Joaquín Xirau."

Pero la influencia de Ortega (referida tanto al fondo como a la forma literaria de filosofar), aunque se advierte ya en los últimos años anteriores a la guerra civil, sólo estará presente de forma total y explícita a partir de los primeros años de exilio americano.

\section{b) Época del witalismo historicista»}

Tras su salida de España, permaneció en territorio francés durante la guerra, asentándose posteriomente en Quito (1938-1941), contratado por su Universidad. Durante los cuatro años que permanece en Ecuador construyó su primer sistema de pensamiento, asentado en el raciovitalísmo de Ortega y en el historicismo de W. Dilthey. ${ }^{10}$

Frente a una metafísica neotomista, apoyada en un concepto de ser y de naturaleza estáticos, su pensamiento se asienta ahora sobre la categoria central de vida, como "realidad radicals, de naturaleza «amiboide», en permanente movilidad, proteica. De ahí que el modo de acercarse y dar cuenta de la esencia de las cosas y del trasfondo último de la realidad histórica tenga que ser una "hermenéutica histórico-vital» o scategorial-vital", cuyo objetivo consistirá en ir desentrañando las categorias que la "vidas va utilizando y encarnando en cada época histórica, como elemento aglutinador y raíz de todas sus expresiones culturales. Se trata, por tanto, de hallar el "plan categorial-vital" o "trascendental-vitals con que la vida unifica y estructura cada época o período historico,"

Utilizando esta hermenéutica, García Bacca advierte que la historia de Occidente ha discumido por tres etapas o tipos de vida, que denomina singular, individuo y persona. 12 Puede advertirse, de este modo, que se da un cierto paralelismo entre el discurrir de la historia (filogénesis) y la maduración antropológica (ontogénesis), puesto que en ambas magnitudes se atraviesan identicas etapas.

Ello es así por cuanto el hombre es un "transfinito"," realidad a medio camino entre lo finito y lo mortal o la nada. Por tanto, es un ser que se halla acometido por una tensión permanente 
entre dos fuerzas extremas: tendencia a la nada, o a ser algo de modo estático y definitivo, y tendencia a ser infinito, Dios en persona. Esta segunda tendencia nos descubre la condición endemoniada del ser humano, condición que no hay que computarla como "pecado entitativo, sino desgracia ontológica» ${ }^{14}$

Esta dinámica «transfinita» se halla también, según García Bacca, inscrita en toda realidad del universo, dinámica, a su vez, potenciada por el hombre, el "transfinitos radical. Él es quien está poniendo a prueba $y$ tensionando, para ver de qué es capaz de llegar a ser, a todo el universo. De este modo muestra el universo su condición "poética", su permanente movilidad y dinamismo, fruto no de una mente visionaria sino de la física más en punta, que ha terminado por armumbar la concepción determinística del mundo para dar paso a una concepción abierta y probabilística. $^{15}$

\section{c) Bajo la influencia de Heidegger}

En 1941, invitado por la Universidad Nacional Autónoma de México (UNAM) para impartir un curso sobre Heidegger (junto con Ortega, que no acudió a la invitación), cambió su residencia de Quito a México, donde permaneció hasta 1946. La presencia de Heidegger en su pensamiento se advierte ya en los primeros años de exilio, pero sólo algunos años después se irá convirtiendo en el suelo filośfico sobre el que construye su segunda etapa intelectual del exilio. ${ }^{16}$

De Heidegger toma la vuelta a la visión ontológica de la realidad, desde la búsqueda del sentido del Ser, a partir de la diferencia ontológica. Desde esta óptica retraduce su concepción vitalista anterior y todas las categorías consecuentes. Entre ellas, las correspondientes a su hermenéutica histórico-vital.
Desde la nueva óptica, se trata de advertir y mostrar los diferentes sentidos del ser que han ido mostrándose a lo largo de los diferentes periodos históricos, puesto que el Ser se nos muestra como tempóreo, «epocal». Esa es la razón y raíz de los acontecimientos históricos, por cuanto ala historia consiste, según Heidegger, en esa sucesión y cambio precisamente de concepciones del universo, proviniendo tales cambios, como de raiz, del cambio de sentido que al ser da cada época. La organización del cuerpo de sentido o interpretaciones que cada época da a los seres, a las cosas, posee un centro ontológico: el sentido del Ser. Dilthey buscó el origen de tales concepciones y de sus cambios en la Vida. Heidegger, metafísico, en los cambios de sentido del Ser (Sinn des Seins) ${ }^{17}$

También en su antropología se produce un cambio entre la categoría de "transfinito" y la de "En-ser" ( $D a$ sein)..$^{18}$ El hombre, en cuanto "En-ser» (Da-sein), es un componente dialéctico de ente (su cara limitada y arrojada al mundo) y de Ser (dimensión indeterminada, dada de modo atemático e inobjetivo). Por ello, el hombre, por lo que tiene de ente es limitado, cosificado, unode-tantos; pero por lo que tiene de ser, es apertura a lo imprevisible, inagotable disponibilidad, abierto a cualquier eventualidad y novedad, a lo infinito. ${ }^{19}$

Otro modo de decirlo: nuestra realidad o sistencia es un equilibrio entre insistencin y ex-sistencia, mezcla de abyección y pro-yección. ${ }^{2 n}$ En definitiva, dice García Bacca, el hombre es un ser que está (Da-sein, En-ser). No posee una naturaleza fija y acabada, sino que puede hallarse y vivirse en diversos estados; esto es, vivir y existir como un Don Nadie, uno-de-tantos, un cualquiera, $O$ ir elevándose al estado de singular, de individuo $\mathrm{y}$, por áltimo, de persona (estado de único e irrepetible). ${ }^{21}$ 
En realidad, como puede advertirse, entre estas dos etapas de pensamiento que acabo de señalar (la influenciada por Ortega y Dilthey, y por Heidegger). no se dan rupturas ni modificaciones excesivamente fuertes, fuera de trasvases categoriales. Pero los horizontes de fondo siguen siendo muy cercanos. En cambio, donde se produce un cambio más significativo, una auténtica "ruptura epistemológican, es en la etapa siguiente, cuando experimente la influencia de K. Marx.

\section{La clave socioeconómica del mundo y del hombre}

El acercamiento al marxismo se produce pocos años antes de 1960. Es el momento en que se halla aposentado en Caracas, su residencia más prolongada. No es fácil señalar las causas que motivaron este salto teórico. Dejando aparte otras menos importantes, señalo dos. La primera, el encuentro con la poesía y la prosa filosófica de A. Machado, donde descubre la invitación a escribir y a filosofar para el Pueblo ${ }^{22}$. Pero, junto a esto se halla el contexto determinante de la situación sociopolítica de Venezuela y de toda Hispanoamérica en su despertar crítico y revolucionario frente a la dominación norteamericana, en la década de los sesenta. ${ }^{23}$

A la luz de este nuevo horizonte cosmovisional, para García Bacca todos sus anteriores planteamientos filosófi$\mathrm{cos}$, al igual que todos los sistemas filosóficos existentes hasta entonces, no han sido más que meras «interpretaciones" de la realidad. Pero de lo que se trata ahora, siguiendo a Marx, es de transformarla. Por tanto, la metafísica que quiera estar «a la altura de los tiempos", tiene que ser, o intentar ser, una metafísica transformadora, o mejor, "transustanciadora".

\section{a) "Transustanciam la realidad, una nueva metafísica}

El hombre, desde que accede a ser tal, se halla en relación dialéctica con el resto de la realidad en que se halla implantado. Pero el tipo de relación no siempre ha sido el mismo. Según García Bacca, el hombre ha ido pasando de un tipo de relación meramente contemplativo, "fenomenológico" (predominio de ojos), como es el caso de la época griega y medieval, a otra postura más activa y transformadora, que se inicia en el Renacimiento, para ser superada por una actitud posterior, propia del momento presente, en que el hombre intenta, y en parte lo está ya consiguiendo, "transustanciar" la realidad, y a sí mismo con ella.

Esta nueva relación presupone e implica una nueva comprensión y ejercicio de la metafísica, que García Bacca presenta en uno de sus libros más importantes y logrados, Metafisica natural, estabilizada; metafísica espontánea ${ }^{24}$ En él quiere adoptar la actitud del notario imparcial que levanta acta de la realidad tal y como ella se nos presenta. Esto es, realiza la función de caltavoz de las cosas, de lo que de metafísica hay ya en el mundo al querle han traído, y que êl no ha creado ni producidos. 25

Asi, el mundo en el que estamos, con el hombre instalado ya en él, se aparece al ojo crítico del filósofo como una realidad unificada de forma sistematizada y campal, pero ordenada en diversos estados o tipos de mundo.

Antes de que el hombre sea consciente de ello e intervenga activamente en su entomo, el universo se halla en un estado neutro, "natural", ontológicamente homogéneo. Ahora bien, este equilibrio queda roto desde que el hombre, con su capacidad de pensar y de actuar, comienza a existir. El simple hecho de pensar y de ser consciente, hace que la 
realidad quede ya transformada por diferentes interpretaciones y sentidos, propios de cada individuo, grupos, época y cultura. Comienza entonces a existir el mundo de lo abstracto, y diversas transformaciones del mundo de lo concreto. Por eso, el universo adquiere una complejidad compuesta por realidades concretas (tipo ente, cosas-ente) y realidades abstractas, conceptuales (tipo ser, cosas-ser).

Pero este tipo de operaciones no pasan de ser opexaciones "ontológicas", consistentes sólo en decir el ser de las cosas, pero no en transformarlas. Ahora bien, el hombre, mucho antes de que haya sido consciente de ello, está ya transformando la realidad, y, por tanto, haciendo metafísica, poniendo la realidad en estado metafísico. Así, "la Metafísica comprendería: a) todo tipo de transformación de ente en ente; b) de ser en ente; c) instrumentos metafísicos, o sea, realidades montadas según proyecto $\mathrm{y}$ designio inventados para hacer de lugar en que ente se transforma en ente, o ser en ente o ente en serm. ${ }^{26}$

El resultado de todo ello es la estratificación del universo en tres cstados: natural, artificial y artificioso, cada uno de los cuales constituido con rasgos bien precisos. El mundo natural ${ }^{27}$ es el que el hombre se encuentra cuando inicia su existencia. Presenta una faz que García Bacca califica de aparencial y neutral, tanto en su condición ontológica como en su referencia a cualquier tipo de verdad, lógica, científica, filosófica, religiosa...

Ahora bien, el estado de mundo natural es propiamente una abstracción, puesto que el hombre se comporta siempre ante la realidad de forma activa y transformadora, por lo que hombre y mundo natural son dos realidades que se excluyen mutuamente.

El mundo artificial ${ }^{28}$ es el resultado de esa acción transformadora del hombre.
El paisaje del mundo artificial va diferenciándose progresivamente del mundo natural Si éste se halla constituido por naturifactos (cosas naturales), el artificial lo está por artefactos y manufactos, novedades entitativas que no poseen esencia (ámbito de lo natural) sino plan (esencia artificial, montada y realizada por el hombre y para que le sirva para algo).

Otra característica del mundo artificial es hallarse montado como un total, no como un todo. Esto es, se halla montado con piezas, no con partes, propio de un todo, como es el caso de un ser vivo. ${ }^{29}$ Por tanto, no valen para el mundo de lo artificial la categorías aristotélicas ni sus cuatro causas. La causa final se convierte en designio, la causa formal en contextura, en la causa material queda reducida la materia a simple material en bruto para a partir del cual construir todo tipo de artefactos; a su vez, la causa eficiente aparece en García Bacca llena de riqueza y complejidad, desglosada en causa eficaz, rectora y ocasionante. ${ }^{30}$ Esta complejidad de lo eficiente se advierte sobre todo dentro del mundo de la cibernética.

Con ser interesante la descripción del mundo artificial, momento en que aparece la extraordinaria capacidad filosófica y literaria, de creación de neologismos, en su empeño por hacer del castellano un instrumento adecuado para filosofar, el interés crece de tono con la descripción del mundo artificioso. En la idea de lo artificioso se unen la perspectiva metafísica y la sociocrítica. Y aquí es donde más directamente se advierte la influencia del marxismo, y la originalidad de su asimilación al sistema personal de García Bacca.

Si el mundo artificial es fruto de la acción transformadora del hombre, basada en la operación trocar en, siendo el fruto de la acción creadora del hombre, el mundo artificioso se basa en la opera- 
ción trocar por. Aparece cuando el hombre hace emerger de las cosas su faz de mercancia, y convierte el mundo en un gran mercado, donde todo se compra y se vende, incluso el hombre mismo, ayudándose del intermediario monetario universal, el dinero, represado y acumulado en capital, por la acción premeditada del capitalista. ${ }^{3 !}$

La construcción del mundo artificioso se debe al aprovechamiento que los capitalistas hacen de la capacidad creadora del hombre, capacidad que de por sí está abierta y dirigida a todos, a cualquiera, nunca a nadie en cuanto éste, como individuo concreto, sino para cualquiera, para uno-de-tantos. En cambio, el plan del capitalista consiste en hacer que valga para $m \hat{\text { (el capitalista) }}$ lo que está creado para todos y para cualquiera. De ahí que García Bacca advierta que el mundo artificioso, o capitalista, está construido sobre una escisión ontológica y antropológica, y consiste, por tanto, en un atentado contra el ser del hombre y de la realidad. Es mucho más, pues, que un mero episodio sociológico y político.

De ahi que si el hombre actual quiere reconducir las cosas hacia metas y situaciones en que el hombre y la sociedad se hallen asentados sobre sus verdaderos cimientos, tiene que "transustanciar» el mundo artificioso y reconducirlo hacia un mundo artificial en el que se superen las escisiones de clases sociales, envoltura de escisiones más profundas.

Por tanto, el ámbito de lo económico representa el factor clave no sólo en el área sociopolítica, sino también en el ámbito de lo metafísico, por lo que «si la metafísica comenzó por ser (y puede continuar siendo) proyecto, designio y decisión de transformar lo físico o natural, apoyándose en él, no hay por qué (fuera de su tantico forzada tergiversación de la palabra) la Metafísica no sea una metaeconómica: trascender real- mente lo económico, apoyándose en él, pues pudiera suceder que lo económico ofreciera para una trascendencia base mejor y más amplia que lo físico (sobre todo, más que lo físico sido y dejado de ser como lo simplemente natural) "s.32

\section{b) Nueva óptica de la hermenéutica y la epistemología}

No sólo la metafísica debe ser contemplada desde la categoría transformación/transustanciación, sino también todo el ámbito de lo epistemológico y hermenéutico, como lo señala en Curso sistemático de filosofia actual. ${ }^{33}$ La historia del hombre y de los saberes han atravesado sucesivas fases en su proceso de maduración, hasta llegar a la etapa más perfecta y acabada: la de transustanciación. Sálo así consiguen ser, tanto la filosofía como las ciencias, actuales, esto es, situarse "a la altura de los tiempos".

Comenzando por la filosofía, ha pasado de ser interpretadora (época griega, limitándose a decir el ser, "onto-logein") para pasar a ser luego transfomadora (desde el Renacimiento), y empezar ya a ser transustanciadora, csto es, no contentarse con cambiar la forma de la realidad sino su ser, su sustancia, haciendo la filosolía de "explosivo» de la realidad. ${ }^{34}$

Este esquema lo aplica también a las demás ciencias. Todas tienen que ir pasando de su condición de meras interpretaciones de la realidad, a transformadoras y luego transustanciadoras..$^{35}$ En realidad, para Garcia Bacca las ciencias (sobre todo la física) son las que, de hecho, han accedido antes que la filosofía al estado transustanciador, por lo que le están sirviendo de modelo y paradigma a seguir en el empeño de llegar a ser actual.

También el tiempo y la historia son dimensiones que deben ascender $y$ de hecho ya lo están haciendo parcialmente) de un estado interpretador y natural a 
un estado artificial y transustanciador. En realidad, en su estado natural la historia no pasa de ser pre-historia. En la pre-historia, el tiempo es una dimensión extrínseca al hombre; fluye de modo pasivo, sin que el hombre se dé cuenta del dominio que puede tener sobre él. Por eso, García Bacca distingue entre el tiempo natural, propio de la pre-historia, y el tiempo artificial, el de la historia propiamente dicha. En la pre-historia, el tierrpo discurre del pasado al presente y al futuro, mientras que en el tiempo artificial, cuando el hombre se va haciendo dueño del decurso histórico, las dimensiones temporales son de categoría superior y pasan a llamarse de forma nueva: pretérito, presencia y ponenir.

La historia y la pre-historia se diferencian también en el tipo de sujeto que la habitan. El sujeto de la pre-historia es el «hombre natural»; el de la historia, el "hombre creador». Asimismo, la pre-historia y la historia están asentadas y construidas por diferentes categorías ontológicas. En la pre-historia, señala García Bacca, se dan presupuestos, hallazgos, hechos históricos y fastos. En cambio, la historia está construida por categorías como material en brito (el tiempo natural), inventos, facta y gesta, que ya no son meros sucesos sino acontecimientos creados y provocados por el hombre creador y dueño de su propia historia.

Entre las gestas históricas que el hombre ha realizado, García Bacca señala los inventos, la humanización, el trabajo,
Ia conciencia social, la division creadora del trabajo, la clase social, etc. La meta de toda la historia será construir la Sociedad sin clases, en la que el sujeto creador ya no lo será en su condición de individuo, sino como perteneciente a la Sociedad, al Todo de la humanidad. ${ }^{36}$

\section{c) Del hombre natural al humanismo positivo ${ }^{37}$}

La realización del hombre, en esta etapa, ya no consiste en llegar a ser único, persona, proceso de autoconstrucción en soledad, ideal defendido en las etapas anteriores. Ahora, para García Bacca, no se alcanza el ideal de hombre al margen del entramado social, aunque tampoco quede diluido en él.

El ser humano es el resultado de una doble relación: con la naturaleza y con los demás hombres, a la vez que ejercita su condición de creador y transustanciador. La concepción antropológica de esta época está conformada por una extraordinaria riqueza y complejidad de matices, imposibles de señalar en unas pocas páginas, ${ }^{38}$ por lo que aquí expondré sólo las líneas maestras.

Como he indicado, el hombre, en la concepción de García Bacca, es el resultado de la confluencia de dos relaciones dialecticas: hombre-naturaleza y hombrehombre. En cada una de ellas, la relación no es estática, sino que se produce dentro de un proceso de ascensión por estados o etapas, según el siguiente cuadro.
Dialecticas

Hombre-Naturaleza

Hombre-Hombre

\section{Etapas de humanización}

Hombre pre-humano

Hombre primero

Hombre primario

Humanismo teorico

Humanismo práctico Humanismo positivo
H. natural

H. transform.

H. creador

Creatura

Señor

Creador
Ateísmo

Comunismo

Sociedad/Humanidad 
Cuando el hombre se enfrenta a la naturaleza, se produce una mutua influencia: el hombre «humanizas a la naturaleza, esto es, la configura a su medida; $y$, por otro lado, el hombre se naturalizan, esto es, alcanza, a través del trabajo transformador, su propia naturaleza y condición. Según García Bacca, tal condición consiste en descubrirse y en llegar a ser "creador", "transustanciador", como ya lo hemos señalado repetidas veces. La mediación de toda esta acción transustanciadora es el trabajo técnico, la técnica, como brazo ejecutor de las chispas de creación que surgen en el hombre. De ahí que la reflexión sobre la técnica vaya teniendo cada vez más peso en el pensamiento filosófico de García Bacca, hasta llegar a límites extremos en sus últimos libros.

En una primera fase de esta dialécti$\mathrm{ca}$, el hombre se comporta ante la naturaleza de modo pasivo, contemplativo y miedoso, creyéndose y comportándose como subordinado a las fuerzas de la Naturaleza y su esclavo (actitud de "por-dioseros). Es la etapa que García Bacca llama de hombre "pre-humano", o tambien «hombre natural $\mathrm{u}$ «hombre primitivos. ${ }^{39}$ En realidad, al igual que ocurría con el "mundo natural», el "hombre natural» no ha existido, es una pura contradictio in terminis, por lo que lo denomina "pre-humano». Lo que constituye la separación de lo humano con lo pre-humano o animal, es precisamente la capacidad de ir más allá de lo natural, transformándolo y poniéndolo a su disposición.

En un primer momento, el hombre se limitará a utilizar la naturaleza para sus propios fines. Este es el primer talante que el hombre ejercita respecto a la naturaleza, con el se eleva y distingue de la naturaleza, "mostrando tal su distinción por servirse de ella para sus fines, resultando o surgiendo así a ser Señor de lo natural».40 Es la fase que
García Bacca denomina «hombre primero\%.

Pero no se llega a ser "propiamente hombre» más que cuando se adviene, en la fase siguiente, a ser whombre primarios, consistente en cinventar la forma de no ser creatura de nada ni de nadie, mostrar con obras, con práctica, que se ha hecho diverso de todo, inclusive de eso suyo, previo, inmediato: ser Señor de lo nutural. Se ha hecho, pues, a sí mismo Creador, ya que creador, a diferencia de Señor, no sólo es distinto de sus productos, sino diverso de ellos, tan diverso que los invierte o los hace inversos: resultan creaturas los que comenzaron por ser creadores", 41

La condición de creador, su característica más específica y definidora como hombre, la ejercita tanto en su relación con la naturaleza (a través de la mediación de la técnica), como en relación consigo mismo y con el resto de los componentes de la especie humana. Veamos esta segunda faccta, que constiturye la segunda dialéctica básica.

El proceso de humanización del hombre, paralelo y simultáneo a la transustanciación de la naturaleza, atraviesa también tres etapas, que. siguiendo a Marx en sus Manuscritos de economía y filosofía, denomina "humanismo teórico», «humanismo práctico» $y$ «humanismo positivo ${ }^{42}$

La fase de «humanismo teórico" se consigue cuando el hombre supera su condición de creatura de la Naturaleza para hacerse Señor y Creador de ella; esto es, rechazar la divinización de cualquier realidad del universo. El hombre tiene que convencerse de que no hay más dios que él mismo, apropiândose para su provecho las propiedades que equivocadamente había atribuido con anterioridad a Dios. Consiste, pues, en "transustanciar" a Dios en provecho del hombre, dándole a la categoría «transustanciación», tan utilizada por García 
Bacca, todo el profundo contenido teórico y provocativo que posee. ${ }^{43} \mathrm{El}$ hombre, para ser tal, tiene que hacerse, pues, ateo. Ahora bien, siendo ateo, el hombre alcanza un tipo de humanidad puramente teórica. Hay que llegar a serlo de modo práctico.

Y lo consigue en la medida en que es capaz de y consigue transustanciar la "propiedad privada»: advenimiento del comunismo. Pero este proceso no se limita a una simple revuelta sociológica para con ella imponer la dictadura del proletariado. Eso no pasa de ser un "comunismo burdo". El empeño de García Bacca consiste en este punto en mostrar todo el contenido ontológico y antropológico que este proceso contiene. Lo más significativo consiste en mostrar que el proceso creador que el hombre pone en marcha a través del trabajo, conlleva como elemento esencial una dimensión interpersonal y social inalienable. De modo que, cuando el trabajador elabora sus productos ("artefactos" y "manufactos"), el destinatario es siempre el ser humano en su globalidad, no en cuanto éste, sino en cuanto cualquiera o tho-de-tantos.

De ahí que la privatización de los productos del trabajo, realizada por los capitalistas, no sólo constituye un proceso alienante y distorsionador de dimensiones sociológicas o legales, sino ontológicas y antropológicas. El capitalismo constituye, por tanto, el proyecto y designio de unos pocos de construir una sociedad de hombres escindidos, escision que se produce tanto entre los proletarios como entre los propios capitalistas, en la medida en que éstos se aprovechan de la condición creadora del trabajador, rebajando su condición de creador a la de mercancía. Al mismo tiempo, el capitalismo escinde y distorsiona la condición humana en la medida en que mantiene al hombre en una situación de aislamiento individualista, cuando su capacidad creadora le habia situado en una condición social y comunitaria. Si Garcia Bacca se esfuerza en mostrar que el trabajo creador lleva inscrita la condición comunitaria y social del hombre, señala al mismo tiempo que en los niveles de shombre natural» y de ahombre primero* el hombre actúa y es realidad individual, a lo más posee una socialidad impersonal. Pero, a medida en que va ascendiendo a "hombre creador», va superando su individualidad para alcanzar la meta más acabada de su realización: la Sociedad como un todo, realidad más compleja que la simple suma de individuos. ${ }^{44}$

Ahora bien, el comunismo, con el logro de la Sociedad, no es la meta final de la historia ni de la humanización. Es simplemente una etapa más, precursora de la etapa definitiva, el ohumanismo positivo». Es su condición necesaria, pero no suficiente. Ia etapa tercera y definitiva sólo podemos simplemente atisbarla y prepararla, pero nunca describirla del todo, ni menos aún conquistarla definitivamente. Se trata de un proceso abierto a lo imprevisible, como todo provenir (futuro construido por el hombre).

Sí se atreve, con todo, García Bacca a indicar que el "humanismo positivo" será una etapa histórica en la que el reino de la necesidad irá siendo progresivamente sometido a la libcrtad del hombre social. Igualmente ocurrirá con el tiempo histórico, que será paulatinamente sometido a los planes de la Sociedad, que alcanzará entonces su dimensión perfecta, la de Humanidad.

Pero, como García Bacca no se cansa de repetir, estos son meros atisbos, intentos de desvelar los rasgos de una utopía que irá construyéndose dentro de una dinámica constituida por lo imprevisible y los golpes creativos (inventos) de la humanidad. 


\section{Distanciamiento del marxismo: el uiltimo Garcia Bacca}

A partir de 1980 , los acentos marxianos van desapareciendo paulatinamente de sus escritos, para centrar su reflexión sobre la realidad desde el prisma y perspectiva de la técnica. Se inicia, por tanto, una nueva época de su pensamiento, caracterizada por un ritmo similar de producción escrita, entre cuyos títulos más significativos hay que situar a $\mathrm{Ne}$ cesidad y Azar. Pamenides (s. V a.c.) Mallarmé (XXX d.C.), ${ }^{45}$ Tres ejercicios literario-filosóficos de antropologia, ${ }^{45}$ y Qué es Dios y Quién es Dios. ${ }^{47}$

Aunque en la época anterior la influencia del marxismo fue sustancial y decisiva, Garcla Bacca nunca se consideró un "marxista» ortodoxo. ${ }^{48} \mathrm{Y}$ tampoco ha tenido problemas ni escrúpulos para cambiar su sistema de pensamiento cuando lo ha creído oportuno, en épocas anteriores. En estos últimos años, con la misma libertad ha dejado de lado los acentos sociocríticos y nos ha mostrado un modo nuevo de entender la realidad, que podríamos denominar tecnocénirico. Si la reflexión sobre la técnica ocupó, ya desde el inicio del exilio un lugar importante en su obra, en la última década de su vida ocupa el lugar central.

De tal modo que la tecno-ciencia constituirá el modo nuevo, "actual», de hacer ontología. Si en épocas anteriores la filosofía, a través de la ontología, tenía como objetivo propio y primordial decimos el ser (conto-logein") de las cosas, ahora ese papel le corresponde y lo está realizando con mayor acierto $y$ profundidad la ciencia y la técnica, en la medida en que son ellas las que nos muestran el auténtico ser, la realidad de verdad de las cosas. Nos descubren sus partículas elementales y la base radial, probabilística e imperecedera (inmortal) de la materia y de lo humano. ${ }^{49}$
De ahí que, frente a la ontología tradicional, que sólo nos puede mostrar el aspecto "parencial" y existencial de las cosas (la simple constatación de "qué son"), la ciencia y técnica actuales nos ponen de manifiesto su ser auténtico, su "realidad de verdad" (su "que son"). Por tanto, llegar a saber la esencia de la realidad material será obra de la "radioontología" (Necesidad y Azar. Pannénides [s. va.C.] - Mallarmé [s, XIX d.C.D; y mostrar en su profundidad la condición del ser humano será propiamente obra dc la "radio-antropologia" (Tres ejercicios filosófico-literarios de antropología); así como el saber acerca de Dios será hacer "radio-teología" (Qué es Dios y Quién es Dios).

En medio de un universo material, constituido en su dimensión última y más profunda por una base radial, probabilística e imperecedera, el hombre a la altura de los tiempos está ejercitando su condición de espoleta del universo (tras haber sido respecto de él simple attavoz y prisma), poniéndolo a explotar, para ver qué da de sí. Y a través de estos golpes transustanciadores y de creación de nuevas realidades, el hombre va mostrando su condición divina y haciendo emerger y transparentarse lo divino del universo, hasta hacerse patente que todo es divino. Este es el resultado final de su "panteísmon peculiar de Qué es Dios y Quién es Dios.

En esta voluminosa obra, síntesis del pensamiento de su última época, se recogen sus más profundos acentos prometeicos que recorren toda su trayectoria filosófica. $Y$ es que una de las vetas más hondas y personales de su pensamiento consiste en entender y concebir al hombre como un proceso interminable e imposible de llegar a ser Dios en persona. Siempre se ha dado en todas las etapas de su pensamiento una estrecha relación entre la idea de Dios y la idea del hombre. El uno se define en 
función del otro, en relación transitiva y biunívoca. Claramente lo expresa, de forma conclusiva, en Qué es Dios y Quién es Dios: "La proposición final de esta obra: qué es (ser) dios y quién es Dios y qué es lo divino (de dios y de Dios) nos ha llevado, sin evasivos, a la cuestión: qué es (ser) hombre y quien es hombre; qué es lo humano (de hombre) y quién es humanamente (hombre). De teo-óntica y teo-logía, a antropo-óntica y antropologían., ${ }^{50}$

\section{Una abra proteica, audaz y multifacética}

La obra y el pensamiento de García Bacca tiene tal pluralidad de facetas, que resulta imposible dar cuenta de todas ellas en un escrito tan breve como éste. Ni tan siquiera con un grueso manual seria suficiente. Hay que leerlo directamente para percibir y experimentar la riqueza de sugerencias, su acertado esfuerzo por moldear el castellano para la filosofia, y la calidad literaria de su prosa, difícil de encontrar en autores dedicados al género filosófico. Aunque también es verdad que su preocupación por la envoltura literaria le hace incurrir con frecuencia, especialmente en sus últimos escritos, en un cierto amaneramiento y barroquismo, que no ayu$\mathrm{da}$ al lector que no se encuentre familiarizado con su prosa. ${ }^{51}$

Si nos preguntamos cuáles son los rasgos más destacados de su filosofar, tendría que plasmarlos en una lista interminable. Sólo me voy a referir a algunos más significativos. En primer lugar, su carácter proteico, en perpetua reestructuración, atento a todo tipo de sugerencias e influencias del más variado abanico de pensadores y materias. García Bacca ha confesado repetidas veces que nunca le ha interesado dar una imagen de coherencia y de intentar anclarse en un sistema bien trabado y permanente. Su filosofía siempre busca dar una imagen de anti-sistema, de permanente renovación y cambio, puesto que así considera que es la vida humana y toda la realidad.

De ahí que más que aportar afirmaciones cerradas y dogmáticas, tenga más interés en ser suscitador de novedades y sugerencias, en hacer pensar al lector, antes que decirle cómo es la realidad. Este talante suscitador ("maliciadors lo llama el) deja a veces al lector en la duda de si habla en serio, o se halla ante una exageración provocativa.

Este talante provocador hace también que sus escritos, y en mayor medida los más recientes, se muevan en el ámbito de un género utópico, entre humanista y tecnocéntrico, fruto de su empeño por llevar hasta el límite el ilustrado grito kantiano sapere aude, que en García Bacca se completa con el marxiano "atrévete a transformar/transustanciar", a poner a toda la realidad a la prueba de ser o no ser. Y sobre todo la propia realidad humana. Porque el hombre es el "atrevido", «espoleta" de sí y del universo.

Su afán desmedido por romper moldes, por no aceptar las cosas como son, hace que podamos considerar a García Bacca como un pensador de fronteras. Su pensamiento se ha mantenido a caballo entre la ciencia y la filosofía. No se ha cansado nunca de repetir, y de practicar, que no se puede filosofar al margen de las ciencias actuales. Este mensaje lo viene repitiendo desde su discurso de inauguración de curso en el Filosofado de Solsona (1929).

Una segunda frontera transitada por él es la situada entre la filosofía y la teología. Venido, por formación juvenil, del campo de la teología, aunque distanciado de ella tras la guerra, siempre ha estado presente en su pensamiento filosófico el punto de vista teológico, la pregunta por la realidad de Dios y la 
concepción del hombre como búsqueda de la infinitud ("transfinito») y como deseo de ser Dios en persona. La cima de csta línea de pensamiento lo constituye Qué es Dios y Quién es Dios (1986). ${ }^{52}$

Una tercera frontera es la que relaciona la filosofía con la literatura. Frontera muy querida y transitada por nuestro filósofo, despertada desde muy joven por influencia de J. Ortega y Gasset, y sobre la que ha dejado interesantes teorizaciones en libros como Introducción literaria a la filosofía ${ }^{53} \mathrm{y}$, más recientemente, en sus variados «ejercicios filosófico-literarios" a que ya hemos hecho referencia, y en una de sus últimas obras publicadas en vida: Sobre El Quijote y Don Quijote de La Mancha. Ejercicios literario-filosóficos. ${ }^{54}$

Y hay una cuarta frontera, la que une y separa la filosofía con la música. Es también un tema que, como los anteriores, aparecen muy tempranamente en sus preocupaciones filosóficas, en el prólogo a introducción al filosofar. ${ }^{55}$ Pero se halla más o menos presente o soterrada en casi todas sus obras, hasta que emerge de una forma madura y complcta en fechas recientes, en su Filosofía de la música. ${ }^{56}$ Este gusto por los terrenos fronterizos y poco transitados no son más que una mostración práctica de que el hombre es para García
Bacca un animal de fronteras, un animal utópico, descontento de sus limitaciones y facticidades, e impelido desde sus propias entrañas a la búsqueda de lo «trans", de lo más allá, de lo imposible.

En ello se muestra también la gran coherencia que siempre ha mantenido García Bacca entre su teoría antropológica y el desarrollo concreto de su obra escrita. Es posible que su afán de novedad, sus ansias de pensar la utopía, su empeño en atisbar y describir el porvenir de lo humano, le llevara, sobre todo en sus últimas obras, a construir un universo filosófico impregnado por una cierta exageración y fantasía, encerrado en sí mismo. Esto es lo que me lleva a afirmar que sus mejores páginas no se hallan en su última época, sino en las obras que se inspiran en suelo filosófico marxista.

Tanto quienes sintonizan globalmente con su pensamiento, como quienes encuentran en él serias limitaciones, tienen que reconocer que nos encontramos ante uno de los más significativos y valiosos filósofos en lengua castellana, por desgracia y desidia no suficientemente valorado, ni suficientemente recuperado del alejamiento que sufrió con el exilio, ni todavía adecuadamente reganado para nuestro exiguo panorama filosófico.
1. Cf J. Gaos, sFilosofia y literatura, scgún un filosofo español", "Sobre Ortega y Gasset y otros trabajos" Cwademos Americanos, n. ${ }^{\circ}$ 173-174 (nov,dic. 1945).

2. Sobre la bibliografía de Garcia Bacca, of. Mireya Perdomo de González, Bibliograffa de Juan $\mathrm{Da}$ vid Garcia Baca, Caracas, Universidad Central de Venezuela, 1981; Revista Anthropos, 9 (1982), 1524; I. Izuzquiza, "La obra escrita de J.D. Garcia Bacca*, Artitropos, 29-30 (1983); y El proyecto filosofico de J.D. Garcti Bacca, Barcelona, Anthropos, 1984; C. Beorlegui, I.D. Garcia Bacca La atidacia de un pensar, Bilbao, Universidad de Deusto, 1988;
G. Díaz Diaz, Hombres y documentos de la filosofía espariola, vol. III, Madrid, CSIC, 1988, pp. 380-392.

3. Cf. C. Beorlegui, J.D. García Bacca. La audacia de un pensar, op. cit; 1 Id., "El pensamiento de J.D. García Bacca, un filosofo navarro desconocido", Principe de Viana (Pamplona), 6, VI (1986), 213-240, Suplemento de Ciencias; fd, al pensamiento filosófico de J.D, Gancía Bacca en el contexto del exilio republicanon, Departamento de Cultu* ra del Gobiemo Vasco (en prensa).

4. Entrevista de $C$. Gurméndez en El País. $22 \pi \times / 1977$

5. Fruto de ellos fue su tesis doctoral en Teolo. 
gía, escrita en latín, como era preceptivo, y titulada De rebus metophysice perfectis, seu de natuma et supposito secundum primum totius philosophiae principizm, Barcelona, Imprenta Claret, 1920.

6. A. Trendall, *Dílogo filosófico con el profesor J.D. Garcia Baccas, Bollvar (Bogota), 34 (1954), 695.

7. Cf. "La filosofia, ciencia de los panoramas intelectuales», Ih siracion del Clero (Madrid), vols. 24 25 (1930-1931).

8. Entrevista de C. Gurméndez en El Pats (16NI11978).

9. Cf. V. Muñoz Delgado, "Notas para la historia de la logica durante la Segunda República española (1931-1939)", Religion y Cultura (Madrid), 26 (1980), 893-931; fd, "La logica modema en los primenos escritos de J,D. Garcia Bacca (1932-1934)", Anthropos (Barcelona), 9 (nueva ediciön) (1991), 54-66.

10. Los libros centrales de esta época son: Introduccion al filosofar (Incitaciones y sugerencias). Tucumán, Univ. Nacional de Tucumán, 1939; Invitación a filosofar, México, FCE, 1940-1942, 2 vols; y Tipos historicos de fllosofar fistico, desde Hesiodo hasta Kant, Tucumán, Univ. de Tucumán, 1941.

11. C. Introduccion al flosofar, op. cit., p. 149.

12. CE. Introducción al filosofar e Invitación a filosofar, vol. 1 .

13. Cf. Introduccion al filosofar, vol. 1.

14. Ibid., p. 11.

15. Cf. La concepción poetica del universo físicon, Cuademos Americanos, 1 (mayo-junio, 1944), 69-81: "La concepción probabilistica del universo cn Mallarmen, Orbe (México), 1 (1945), 35-58; *Heráclito $y$ el indeterminismon, Asomante (Puerto Rico), 2, III (1947), 5-8.

16. Los escritos pertenecientes a esta etapa constituyen un conjunto de artículos que mas adelante publicô bajo el título genérico de Existencialismo, Xalapa (México), Universidad Veracruzana, 1962. (Nueva edicion: Barcelona, Anthropos, en preparación.)

17. GB, *Heidegget o el modo de filosofar existencials, Asomante (Puerto Rico), 3, 4 (julio-sept., 1945), 11-32; 32 ss. Los subrayados son de GB.

18. CE. Las ideas de ser y estar de posibilidad $y$ reatidad en la idea del hombre en la filosofia actual, Barcelona, Laye, 1955.

19. Cf. Existencialismo, op. cit., p. 253.

20. Cf. Thid, pp. 133 y 118 y ss.

21. Cf sobre todo Las ideas de ser y estur.., op cit.

22. CE aGlosas filosoficas a unos versos de $A$. Machadon, Revista Nactotzal de Antioqtia (Medellín) (1959), 5-13; e Invitacion a filosofar seguin espfriu y letra de A. Machado, Mérida (Venezuela), Universidad de los Andes, 1967 (nueva edición en Anthropos, Barcelona, 1984).

23. Es esclarecedor leer sus artículos criticos contra la aAlianza para el Progresos y la dominación de los Estados Unidos, en Ensayos, Bar- celona, Peninsula, 1970, pp. 21 y ss; y 36-38. (Nueva edición: Barcelona, Anthropos, en preparacion.)

24. México, FCE, 1963.

25. Ibid., p. 7

26. Ibid, p. 132.

27. Cf. su descripción completa en Metafísica natural estabilizada y problemática, metafisica espontänea, México, FCE, 1963, pp. 158-183.

28. Cf. Metafisica, pp. 183-209.

29. Un Todo está todo en el Todo, y todo él en cada una de sus partes; mientras que un Total está todo en el todo, mas no está todo en cada una de sus piezas", Metafísica, p. 191.

30. Cf. Metafísica, pp. 200-205.

31. Ibid, p. 301.

32. Iltid, p. 327 .

33. Caracas, Universidad Central de Venezuela, 1969. Este libro viene a ser el complemento de $M e$. tafisica, y uno de sus libros fundamentales.

34. Cf. ibid, 17-28. Desde este punto de vista escribe sus lecciones de Fistoria de la Filosofla, 2 vols., Caracas, Universidad Central de Venezuela, 1972-1973.

35. Cf. Curso sistematico.., pp. 29-49; Teoria y metateoria de las ciencias, 2 vols., Caracas, UCV, 1977; Elementos de filosofia de las ciencias, Caracas, $\mathrm{UCV}, 1967$.

36. Cf. Curso sístemático..., pp. 51- 128.

37. La concepción antropológica de esta etapa se halla expresada, además de en Metafisica y Curso sistematico, en Humanismo teorico, práctico y positivo, seguin Marx, Mexico, FCE, 1965; Invitación a filosofar segtin espiritu y letra de A. Machado, Mcrida (Venezuela). Universidad de los Andes, 1967; Elogio de la técnica, Caracas, Monte Ávila, 1968 (nueva edicion: Barcelona, Anthropos, 1987); y Lecciones de Historia de la Filosofia, Caracas, UCV, 1972, en especial el capítulo dedicado a K. Marx, vol. 2 .

38. Cf. C. Beorlegui, La ided del hombre en J.D. Carla Bacca, Bilbao, Universidad de Deusto, tesis doctoral, 1983; Id., García Bacca. La audacia de un pensar, op. cit.; fd., "El hurmanismo utopico de J.D. García Bacca», Anthropos (Barcelona), 29-30 (1983), 80-88.

39. Cf. «Elogio de la técnica», op. cit., p. 85.

40. Ibid, p. 86 .

41. Ibid, p. 86. Los subrayados son de GB.

42. Cf. su contenido completo en Humanismo leónico..., op cit.; Lecciones de Historia de la filosofia, op. cit., vol. 2, cap sobre Marx; y Cusso sistematico de fllosofia actual, op. cit., parte II, cap. 1 . pp. 159 y ss.

43. CE. Humanismo teorico..., pp. 14 y ss.

44. $C E$ " ¿Qué es Sociedad? (Ensayo de definirla cientifica y ontologicamente)», Sistena (Madrid), 4 (1974). pp. 7-22.

45. Barcelona, Anthropos, 1984.

46. Barcelona, Anthropos, 1984. 
47. Barcelona, Anthropos, 1985.

48. Cf. Entrevista con Juan David García BacCan, Resumen (Caracas), 321, XXV (1979), 52-63.

49. Cf. Vida, muerte e inmortalidad, Caracas, UCV, 1983; y Transfinitud e inmorialidad. Caracas, Josefina Bigott Ldit., 1984.

50. P. 533. Los subrayados son todos de García Bacca.

51. Me refiero sobre todo a los diversos «ejencicios literario-filosóficos" de dialéctica, economía, antropologia, moral, etc., publicados todos ellos por la Ed. Anthropos de Barcelona, en la última decada.

52. CE. C. Beorlegui, sa evolución de la idea de
Dios en Garcia Bacca», que aparecerä en Iglesia Viva.

53. Caracas, UCV, 1964, Cf. C. Beorlegui, «La presencia de Ortega en el pensamiento de J.D. García Baccan, Letras de Deusto, 40, 18 (1988), 93-117.

54. Barcelona, Anthropos y Pamplona, Gobiemo de Navarra, Departamento de Educación, 1991.

55. México, El Colegio de México, 1940.

56. Barcelona, Anthropos, 1990. Un estudio completo sobre la filosofía de la música en García Bacca representa la tesis doctoral de Miguel A. Palacios Garoz, "Filosofía en música y filosofía de la música", presentada en la Universidad de Vallado. lid, en 1990. 